\title{
Relationships and Hybrid Contracts: An Analysis of Contract Choice in Information Technology ${ }^{1}$
}

\author{
Arturs Kalnins \\ University of Southern California \\ Kyle J. Mayer \\ University of Southern California
}

Selecting the type of contract is an important aspect of governing interfirm transactions. The purpose of this article is to examine the use of fixed-fee and time-and-materials (T\&M, or cost-plus) contracts and a hybrid contract that consists of a T\&M contract with a cap. In addition to uncertainty and measurement factors, we also address a relatively unexplored aspect of contracting-how the prior relationship between the firms influences the type of contract the firms select. Using data on 394 contracts from the information technology (IT) services industry, we show that T\&M contracts are preferred when the cost of measuring quality ex post is high and when it is difficult to estimate costs ex ante. We also find site-specific measures of relationship lead to a preference for tow-powered T\&M contracts.

\section{Introduction}

Contracts have been the subject of theoretical and empirical work in agency theory and transaction cost economics for more than 30 years. Most of the contract literature, beginning with Cheung (1969), has focused on risk allocation and agency Issues as the fundamental determinants of contract choice. Following Cheung, other theoretical and empirical work on contract choice has examined a variety of determinants of contract choice, including measurement costs (Allen and Lueck, 1993), double-sided moral hazard (Lafontaine, 1992), enforcement costs (Allen and Lueck, 1992a), supervision costs (Alston, Dutta, and Nugent, 1984), and the role of financial constraints (Laffont and Matoussi, 1995). Furthermore, most theory on contracting has focused on attributes of the current exchange rather than the history of interaction between the two parties. While sociologists and organization theorists have long argued that business transactions are strongly influenced by relationships and social context (e.g., Granovetter, 1985; Gulati. 1995; Adler, 2001), and while institutional economists have similarly incorporated relationships into their arguments (e.g., Williamson, 1979), empirical researchers have only recently examined how relationships affect the choice of contractual form (e.g., Bancrjee and Duflo, 2000; Poppo and Zenger, 2002; Corts and Singh, 2003).

In this article we analyze the role of uncertainty and measurement issues and the prior relationship between the parties on the use of fixed-fee contracts, time-and-materials (T\&M. or costplus) contracts, and hybrid contracts (a T\&M contract with a cap). There is currently no consensus in the

\footnotetext{
${ }^{1}$ We would like to thank Luis Garicano, Tom Gilligan. Julia Liebeskind. John Matsusaka. Jackson Nickerson. Brian Silverman, Michele Williams, and two anonymous reviewers for making helpful suggestions.
} 
literature regarding how a prior relationship influences contract choice. We examine the magnitude of the prior relationship and explore different ways to measure the prior relationship between two firms.

We analyzed a sample of 394 contracts written by a large supplier (hereafter referred to fictitiously as Compustar) in the information technology (IT) industry. In these IT contracts, the supplier is contracted to perform some type of service involving equipment in the buyer's data center or some other component of the buyer's IT networking infrastructure (e.g., mainframes, storage devices, servers). Each contract represents a separate project for which Compustar supplied a distinct service for the buyer. The contracts, along with interviews with several of the firm's managers and engineers, allow' us to analyze the determinants of contract choice.

The article is organized as follows. The next section briefly discusses the extant contracting literature. The third section describes the three types of contracts prevalent in IT and develops predictions regarding the determinants of choice among them. The remaining sections describe the data, methods, and results of our analysis. Ordered probit analyses were employed to evaluate how the choice of contract type is affected not only by relationships but also by ex ante cost uncertainty and ex post quality measurement. We conclude with a discussion of our results and the implications for future research.

\section{Literature Review}

Contracting has been the subject of a great amount of theoretical and empirical analysis [see Boemcr and Macher (2002) and Shelanski and Klein (1995) for overviews of the empirical work on contracting]. Work in this area has examined different types of contracts and contract clauses and the factors that lead to their use in a variety of settings. Studies of contract choice typically analyze the choice among various types of contracts, usually cost-plus contracts and fixed-fee contracts (e.g., Eswaran and Kotw al, 1985; Allen and Lueck. 1992a. 1992b), and examine attributes of the current transaction to determine the optimal contract.

The effect of relationships on contracting has been a subject of recent debate. Institutional economists have also long acknowledged that long-term relationships are ideal for certain transactions (Williamson, 1979). Sociologists generally have concluded that relationships decrease the reliance on contracts due to an increase in trust between the parties (e.g.. Ring and Van de Ven, 1994: Gulati, 1995; Adler, 2001). Recent theoretical work in institutional economics, however, has found that relationships and contracts can complement one another (Baker, Gibbons, and Murphy, 1994).

Recent empirical studies have also investigated this issue, but they have not arrived at consistent conclusions. Corts and Singh (2004) found that as partners interact repeatedly in the offshore oil-drilling industry, the parties are more likely to use a contract with weaker incentives, such as a T\&M contract. Chisholm (1997) finds a similar effect in the case of contracts between movie stars and producers. On the other hand, Mayer (1999) found that better relationships and strong incentive contracts are complements in a case study of software contracting. Further, Poppo and Zenger (2002) and Ryall and Sampson (2003), using surveys from the information services industry and a sample of technology alliance contracts, respectively, found that better relationships and contract complexity are complements. Banerjee and Duflo (2000) found no significant effect of partner experience on the 
contractual form chosen, but they did show that Indian software firms with more established reputations rely more on cost-plus contracts, while younger, less established firms are more likely to use fixed- fee contracts with stronger incentives.

In this article we build on tills literature by examining the influence of relationships on three contract types. While previous articles have used binary measures (Chisholm, 1997; Bancijee and Duflo, 2000), counts of previous contracts (Corts and Singh, 2004), and survey items regarding buyer and supplier perceptions (Poppo and Zenger, 2002) to capture the extensiveness of relationships, we examine the magnitude of prior business between the firms at both the site and corporate levels.

\section{Variation of Contractual Form in Information Technology}

We focused on three types of contracts in use in a wide variety of industries: fixed-fee contracts, T\&M contracts, and T\&M contracts with a cap (hybrids). Fixed-fee contracts consist of a lump-sum payment in exchange for the completion of services as specified by the contract. T\&M contracts (also known as cost-plus contracts) involve the buyer directing the supplier to work on a particular task in exchange for a specified amount per hour or per day plus expenses. Executives in the IT industry who were interviewed for this study indicated that T\&M contracts were often employed so that work could begin without a full identification of project scope. The total price in such cases is not predetermined, so the supplier can more easily pass on any costs resulting from buyer-requested changes. The lack of a fixed price also means that the buyer bears the financial risk of the project coming in over budget.

Placing a "cap' on a T\&M contract creates a hybrid contract that combines the features of T\&M and fixed-fee contracts. This type of hybrid contract is used in many industries to balance incentives for cost efficiency and quality (Bercnds, 2000). Reichelstein (1992:713) quoted a General Accounting Office (GAO) report that concluded that such hybrid contracts would be appropriate w here "'the government has a sound basis to estimate costs, but $w$ here uncertainties exist that make a fixed-price contract impractical' (GAO, 1987,1)." This type of hybrid contract can also be valuable to buyers because it provides an upper limit on their exposure, an attribute that can facilitate budget approval.

\section{Determinants of Contract Choice}

We argue that two types of measurement issues are particularly relevant for contract choice: ex ante uncertainty over expected costs and the cost of measuring quality ex post. In addition, we explore the effect of the prior relationship between the buyer and supplier on the choice of the current contract. We will now examine how each of these factors is likely to affect contract choice.

\subsection{Ex Ante Uncertainty Regarding Actual Cost and Project Specification}

Fixed-fee contracts provide suppliers with strong incentives to operate efficiency because the supplier bears all cost overruns. Allowing the supplier to keep the results of any cost savings also creates strong incentives for suppliers to autonomously adapt to external changes in technology or input prices 
that can lower costs. This creates stronger incentives to innovate in the area of cost reduction than are present in a T\&M contract.

When a project is complex, total cost becomes difficult to estimate in advance and the exact specification of the final output is difficult to define. In such cases, fixed-fee contracts become problematic, as variations from the agreed-upon requirements require costly renegotiation. Bajari and Tadelis (2001) and Corts and Singh (2004) argued that a primary benefit of a T\&M contract, relative to a fixed-fee contract, is the reduced cost of renegotiation. In Bajari and Tadelis' model, the supplier's private information about the cost of any proposed changes leads to a positive probability that the contract renegotiation will fail in the case of fixed-fee contracts. Tills probability increases with contract complexity. In T\&M contracts, this possibility is removed by the fact that the supplier is always guaranteed a nonnegative return as long as the original project scope is adhered to. More generally, in the case of T\&M contracts, as requirements change, the buyer is more likely to be able to persuade the supplier to incorporate the necessary changes without any need to renegotiate the initial contract. Thus T\&M contracts facilitate adaptation to changes after the project is under way.

We also argue that when uncertainty is at an intermediate level the parties may choose to employ a hybrid T\&M contract with a cap. On the one hand, as long as the cap is not exceeded, the hybrid contract contains the renegotiation benefits of the T\&M contract. On the other hand, the incentive benefits of a fixed-fee contract are available after the cap has been reached. It is therefore likely that fixed-fee contracts will be used when costs are easy to estimate, T\&M contracts with a cap will be used when there is some level of difficulty in estimating costs, and T\&M contracts will be used when costs are very hard to estimate.

\subsection{Cost of Measuring Quality Ex Post}

A related issue that plays a role in the choice of contract type is the ability of the buyer to measure quality after the task has been completed. Analyses of the impact of moral hazard on economic organization date back to Holmstrom (1979). Because the supplier has incentives to underprovide quality and to operate efficiently under a fixed-fee contract, the buyer's ability to verify the level of quality ex post is important. Anderson (1985) showed that if performance evaluation of a sales agent was difficult, for example, the firm preferred a lower-powered employment contract to a higherpowered contract with an independent sales agent in order to mitigate the incentive to shirk responsibilities in the area of quality. If the potential for latent problems or hidden defects is high, than a fixed-fee contract is problematic. Suppliers have a strong incentive to reduce quality in ways that buyers cannot easily detect if by doing so they can reduce the cost of the project. Low-powered contracts such as T\&M reduce this problem. In fact, T\&M contracts may create an incentive to oversupply quality in order to increase costs that can be passed along to the buyer to increase revenue for the project.

As with the presence of ex ante uncertainty over expected costs, when measurement costs are at an intermediate level, hybrids may be an effective alternative to the two polar forms. At moderate levels of ex post measurement costs, the existence of a cap on the buyer's exposure may be more attractive than a fixed-fee contract because of the weaker incentives for the supplier to underprovide quality. 


\subsection{Prior Relationships and Contract Choice}

Sociologists and organization theorists have long argued that business transactions are strongly influenced by relationships and social context (e.g., Granovetter, 1985; Gulati, 1995), and institutional economists have offered similar arguments with different implications (e.g., Williamson, 1979; Baker, Gibbons, and Murphy, 1994; Argyres and Liebeskind. 1999). There are several mechanisms through which relationships may influence contract choice. First, the parties now have experience with the other party honoring a commitment. If they choose to enter another contract, it is because they think the other party can be trusted and will deal honorably with any unexpected contingencies that arise. Second, when two firms work together for the first time, they have to establish norms of interaction that take some time to set up. Prior interaction helps firms learn how to work with one another more effectively. Third, the previous contract can be seen as a template in terms of what clauses and language to include in order to facilitate approval by management of both parties. Finally, the promise of future business is greater with repeat customers, so the supplier has every incentive to be honest and flexible in order to win more future business from the customer. Since the cost of shirking, in terms of future business lost, is higher, the supplier is less likely to allow it to occur.

Corts and Singh (2004) explicitly theorized about the effects of relationships on contract choice. They held that the effect of relationships on the binary choice between a fixed-fee and T\&M contract is not determinable based only on the length of the buyer/supplier relationship. Long relationships are likely to decrease renegotiation costs, making fixed-fee contracts more attractive. However, long relationships are also likely to reduce costs stemming from supplier shirking, implying that a T\&M contract is to be preferred. Thus, whether long relationships lead to more fixed-fee or T\&M contracts depends upon which type of cost decreases more quickly.

Hybrid contracts may be used when the relationship between the buyer and supplier has not yet developed that is, when there have been few interactions between buyer and supplier. We extend Corts and Singh's (2004) argument above regarding the decrease of both renegotiation COSLS and the costs of shirking. A relationship may decrease these costs and increase the accuracy with which these costs can be assessed ex ante (i.e., the relationship will also decrease the variance of the costs). The idea that repeated interactions will decrease variance in contracting costs, such as those associated with renegotiation or shirking, has foundations in both organizational economics and organizational behavior research. For example, Williamson (1979:240) stated that through repeated transactions, "specialized language develops as experience accumulates and nuances are signaled and received in a sensitive way." Furthermore, Williamson (1999:1104) states, "both parties learn better about the nature of the contractual hazards and of their abilities to communicate and their propensities to cooperate." Finally, organizational behavior researchers (e.g.. Ring and Van de Yen, 1994) have argued that repeated interaction leads to a congruence of values and expectations. Improved communication and value congruence both may decrease renegotiation costs and likelihood of shirking for future contracts.

As a result of the high variance of negotiating and shrinking costs in a new relationship, the buyer would be uncertain about which of the polar contracting forms would cost less, and the hybrid form provides some insurance against the costs of both types of contracts. As the variance of both cost types decreases with repealed interaction, eventually the insurance function of the hybrid form may become less valuable, and thus its use should decline. 
The preceding analysis assumes that prior interaction leads to good relationships, but this is not always the case. If poor interaction leads to termination, then interaction always leads, ultimately, to strong relationships. Williamson (1999:1104) commented that "learning [from repealed interaction] will have a bearing on contract renewal... Serious dissatisfaction on the part of buyer or supplier could result in nonrenewal." However, it may be the case that disputes arise but the parties work through them and learn more about one another as a result, which could lead to a desire for more flexible future contracts or to contracts with more safeguards (e.g., Crocker and Reynolds, 1993). We believe that disputes will more likely simply lead to termination in the IT industry, however, because of the ready availability of alternative suppliers.

\section{Data}

We tested the implications of the arguments above with data from Compustar, a provider of a variety of IT services and computer-related hard- ware. The IT industry involves the storage, transfer, and management of information, typically using mainframes, servers, or related devices. IT suppliers, such as Compustar, perform a variety of IT projects for their customers that include, but are not limited to, designing customized software systems, updating and maintaining existing software or hardware systems, and assisting with network design and security. The technological areas included in this industry are many and include, but are not limited to, areas such as IBM-compatible mainframes, OS/390 programming. Sun systems, databases (e.g., Oracle, Informix), customized software support, and development in a variety of languages.

Compustar was historically a manufacturer of mainframes and related devices (e.g., storage processors) with a strong, technically oriented customer service organization. Compustar entered the platform-independent IT services business in the mid-1980s, and by 1997 its IT services division accounted for revenues approaching $\$ 100$ million worldwide. The firm provided services only for their proprietary platforms before this time. Compustar's IT service contracts do not include large IT outsourcing deals that involve the supplier operating the buyer's data center or outsourcing all IT functions.

Compustar provided us access to all IT service contracts in their corporate contracts library. The contracts date back to 1986, when Compustar first began offering IT services, and run through early 199S. While we had access to all of the contracts, time and resource limitations enabled the coding of only 405 contracts in this dataset, corresponding to all contracts between Compustar and a random sample of 141 buyer firms. We had to eliminate 11 contracts that did not fit into one of the three designated contract types (and two buyers that only used such non-standard contracts), which left an analysis of 394 contracts with 139 North American buyers. Detail regarding the type of contracts chosen and the number of 
Table 1. Contracts by Type and Magnitude of Buyer Relationship

\begin{tabular}{lrrrr}
\hline & FF & Hybrid & T\&M & Total \\
\hline Corporation-specific relationship & & & & \\
$\quad$ Buyers with 1 project & 43 & 13 & 17 & 73 \\
Buyers with 2 projects & 30 & 4 & 12 & 46 \\
Buyers with 3 to 5 & 57 & 7 & 48 & 112 \\
Buyers with 6 to 10 & 58 & 4 & 27 & 89 \\
Buyers with 11+ & 38 & 14 & 22 & 74 \\
Total & 226 & 42 & 126 & 394 \\
Site-specific relationship & & & & \\
Buyers with 1 project & 54 & 13 & 18 & 85 \\
Buyers with 2 projects & 31 & 5 & 16 & 52 \\
Buyers with 3 to 5 & 61 & 12 & 54 & 127 \\
Buyers with 6 to 10 & 55 & 5 & 37 & 97 \\
Buyers with 11+ & 25 & 7 & 1 & 33 \\
Total & 226 & 42 & 126 & 394 \\
\hline
\end{tabular}

contracts signed by each buyer at the corporation level and the site level are presented in Table I. As shown in the table, 73 corporations (or $18 \%$ ) and 85 sites (or $22 \%$ ) have only signed one contract with Compustar. Three corporations with more than 10 contracts each signed a total of 74 contracts. The two sites with more than 10 contracts signed a total of 33 contracts.

Each contract contains a detailed description of the project, the type of service required, and the responsibilities of the parties. A typical contract is about five pages long and is designed to accomplish a specific task for the buyer. Project duration ranged from one week to a year, and project value ranged from approximately a thousand dollars to several hundred thousand dollars. Only three are more than $\$ 1$ million. In addition to reading the contracts, we interviewed several Computer managers and other IT personnel to provide supporting data for this analysis.

\subsection{Variables}

The dependent variable is the choice among the three contract types for each project. The independent variables include proxies forex ante uncertainty about cost and specification, ability to measure quality ex post, and the prior relationship between the firms.

We first focused on four variables related to the complexity of the current project and the resulting ex ante uncertainties. Our first variable was a binary variable for whether projects involve programming. Compustar is relatively new to programming, as it has historically been a hardware manufacturer, and thus estimation of programming projects is likely to be less accurate. Our second variable was a binary variable indicating whether the project involves working on Compustarmanufactured hardware. Compustar is easily able to estimate total project cost and more precisely 
specify the final deliverables when the project involves working on hardware that they have manufactured. Our third variable was a dummy indicating whether Compustar would be working with the buyer's mainframe. Mainframes are particularly difficult to work on if they have not been maintained properly or if they have been heavily customized. While Compustar's expertise in working on mainframes makes them fully capable of dealing with whatever they find andcompletingtheprojcct.it provides only limited help in estimating the cost because of the importance of how the buyer has configured and maintained the machine. Our fourth variable captures a situation in which uncertainly about expected costs is low. Compustar personnel coded a dummy variable that indicated whether their proprietary technology was required to complete the project. Compustar engineers created a list of proprietary technologies that were developed internally. Since Compustar developed these technologies, they are very familiar with their quality and the costs of using them. Two engineers coded the variable based on their expertise and the records in the contract file.

Projects for which Compustar cannot easily measure quality ex post create measurement costs. The variable we employed captured whether the technology used in the project made it difficult to determine the quality of the output generated by the project team. To limit the amount of time engineers had to put into the coding effort. Compustar stipulated that the variable be coded as a binary variable equal to one if quality was difficult to determine and zero if it was readily apparent. The question that determined the value of this variable was whether a brief, inexpensive test or inspection could determine the quality of the work done on the project.

To make sure that these variables were not subject to the biases of a single individual, two engineers coded the same SO contracts (randomly selected) and then compared how they coded the variables for the all measures of contracting hazards and capabilities. Three disagreements were found for measurement quality and two for programming. After a brief discussion, the engineers clarified the discrepancies and felt very comfortable that they were using the same criteria to code the rest of the contracts.

To capture the influence of the buyer-supplier relationship, we used two alternative concepts based on dollars paid by a buyer to Compustar for previous projects. We had valid estimated cost information for 305 of the 394 contracts in our sample. When any of the other 89 contracts without estimated cost information was a previous project for a buyer, we simply added the mean project value of $\$ 83,646$ to the total cost of previous projects. Our first relationship variable was corporation specific; we measured the total dollars (in $\$ 100,000$ s) spent by a buyer corporation on previous IT projects with Compustar (the entire history of each Compustar-buyer relationship). A second variable was site specific: we counted the previous IT project dollars paid to Compustar by each buyer, counting each state $w$ here the buyer's firm has locations as a separate "buyer." The largest buyer firm in our sample, for example, has locations in eight different states that have purchased IT services from Compustar. A partner at a large IT supplier related to us a case in which a senior IT manager with a buyer firm expressed substantial surprise when told how many projects the buyer had undertaken with that IT supplier. The buyer's manager had no know ledge of a large majority of projects undertaken by different locations of his own firm. Based on this anecdote and empirical work on the flow of information (e.g., Adams and Jaffe. 1996). We believe it is very unlikely that sites of the same buyer corporation on opposite coasts, for example, are aware of the contracts signed the other location, making our sitespecific variable the more accurate test of a relationship. Even if executives were aware of contracts in 
different regions with a supplier, it is unclear how large an effect these distantly signed contracts would have on the next contract the firm negotiates with that supplier.

We included buyer-specific fixed effects in some regressions as a control. However, because a large number of observations had to be removed (those where all contracts selected by a buyer were of the same type) when using fixed effects, we also used an alternative approach to control for buyerspecific effects and/or possible path dependence in the relationship. We included a measure for the type of contract chosen for prior exchanges between Compustar and the buyer in some regressions. We split a simple count of previous contracts into separate variables based on the type of contract chosen on those previous projects. Thus we constructed separate variables for the previous projects that are fixed-fee, hybrid, and T\&M. These variables were constructed both at the corporation-specific level and at the site-specific level for each buyer. Finally, to control for changes in Compustar's use of contracts over time, we included a linear time trend variable, setting the year 1986 to zero.

Table 2 contains descriptive statistics and correlations for all variables, from which we can observe some of the hypothesized relationships in the raw data. For example, programming and customer mainframe projects are positively correlated, 0.46 and 0.09, respectively, with the use of the low-powered T\&M contracts. Projects using Compustar's hardware and proprietary technology are positively correlated with the use of fixed-fee contracts, as predicted. The site-specific "Previous IT Dollars" variable is positively correlated with T\&M contracts, though less so than the variables capturing project attributes.

\section{Methods and Results}

Since there are three types of contracts, we used an ordered probit formulation to examine contract selection. The log-likelihood function of the ordered probit for our three ordered alternatives can be written as follows:

$$
L L=\sum\left((h y-f f) * F\left(t_{1}-b_{1} X\right)+(t m-h y) * F\left(t_{2}-b_{2} X\right)+t m\right),
$$

where $f f$ a binary variable indicating a fixed-fee contract, HY similarly indicates a hybrid contract, and $t m$ represents a T\&M contract. The threshold values are denoted by $T_{1}$ and $T_{2} ; X$ is the vector of independent variables; $B_{1}$ and $B_{2}$ are the vectors of slope coefficients to be estimated corresponding to the crossing of thresholds $t_{1}$ and $t_{2}$, respectively; and $F$ represents the cumulative normal distribution. 


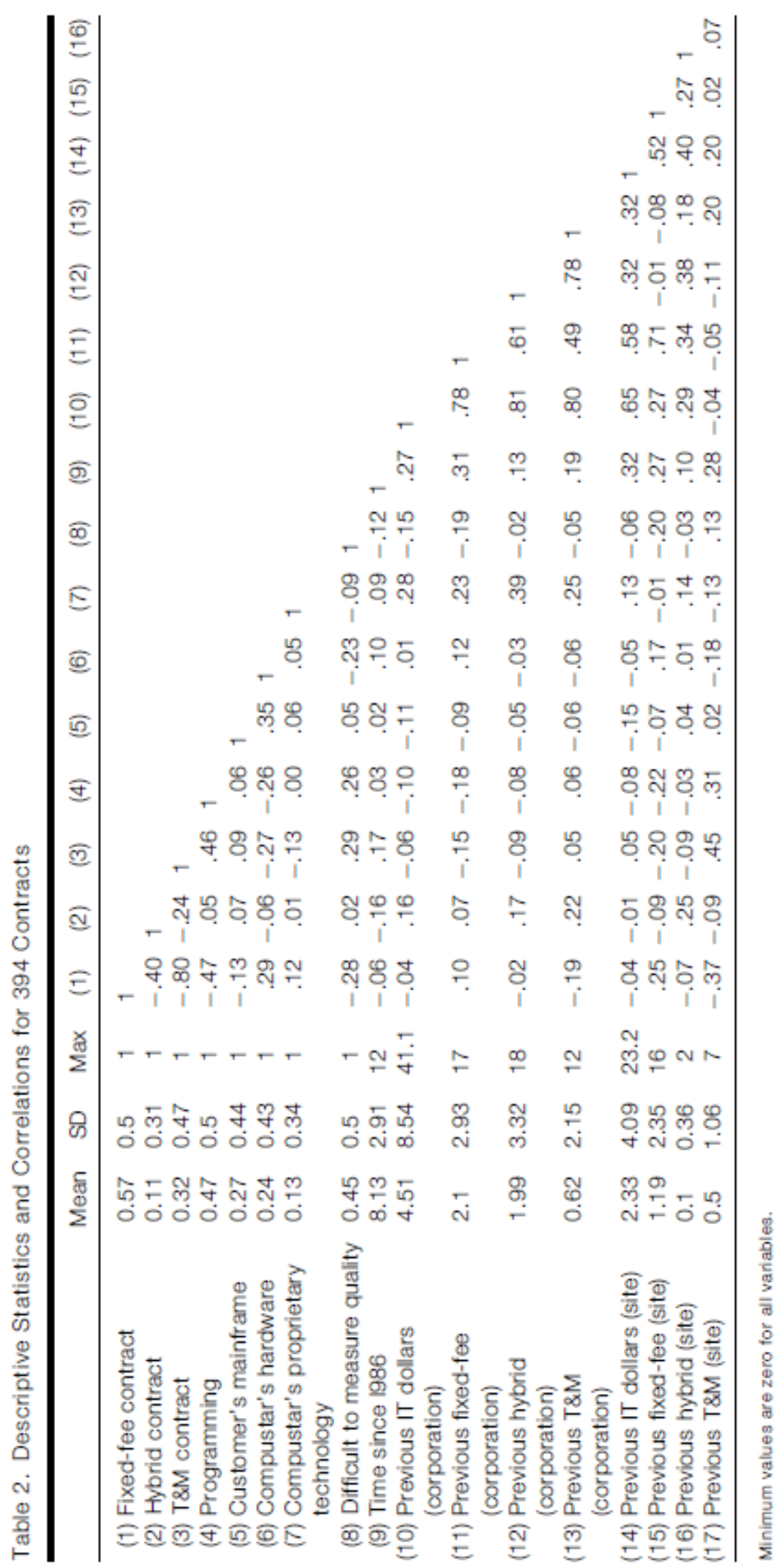


The ordered probit, as typically used by other studies of hybrids such as Baneijee and Duflo (2000) and Crocker and Reynolds (1993), imposes a constraint on Equation (1) that $B_{1}$ and $B_{2}$ are identical. The practical implication is that extreme values of independent variables cannot lead to a preference for the intermediate form hybrid contracts in our study. The six regressions in Table 3 impose this constraint. We also explore whether extreme values of some independent variables might lead to a preference for the intermediate hybrid contract. To do so we estimated ordered probit regressions in which $B_{1}$ and $B_{2}$ were allowed to vary. The eight columns of Table 5 present the results of four regressions in which all variables were allowed separate coefficients across the two thresholds.

Turning now to the results presented in Table 3, the first four columns present regressions using all 394 contracts with 139 suppliers, while the last three columns present fixed-effects regressions including only contracts with buyers that exhibit "within-relationship" variation of contract type. The regression presented in column 5 analyzes 222 contracts with corporation-specific fixed effects for 34 buyers. Seventy-three buyer corporations had to be excluded because they only had one contract with Compustar, and an additional 32 buyer corporations were excluded because all their contracts selected were of the same type. The regression presented in column 6 analyzes 206 contracts with site-specific fixed effects for $3 S$ buyers. Eighty-five buyer sites had to be excluded because they only had one contract with Compustar, and an additional 35 buyer sites were excluded because all their contracts selected were of the same type. Fixed- effects versions of the regressions in columns 2 and 4, which include the counts of the previous contract types, could not be estimated because the within-buyer variations of the previous contract count variables were too highly correlated (consistently more than 0.8 ) with each other and with the respective previous dollar variable.

Four variables were used to examine the effect of ex ante cost uncertainty and project complexity on the choice of contract. As predicted, the use of Compustar's hardware and proprietary technology, indicators of lower ex ante cost uncertainty, increased the probability of observing a fixedfee contract. In addition, programming projects and those that involved a customer's mainframe, indicators of higher uncertainty, led to a greater probability of observing a T\&M contract. Results for all four of these variables supported the prediction that decreases in project complexity and expected variance in cost would lead to T\&M contracts. Greater difficulty in measuring quality ex post led to a greater likelihood of observing a T\&M contract. This provides support for the prediction that ex post measurement costs lead firms to substitute away from fixed-fee contracts and move toward T\&M contracts that decrease the incentive to underprovide quality. 


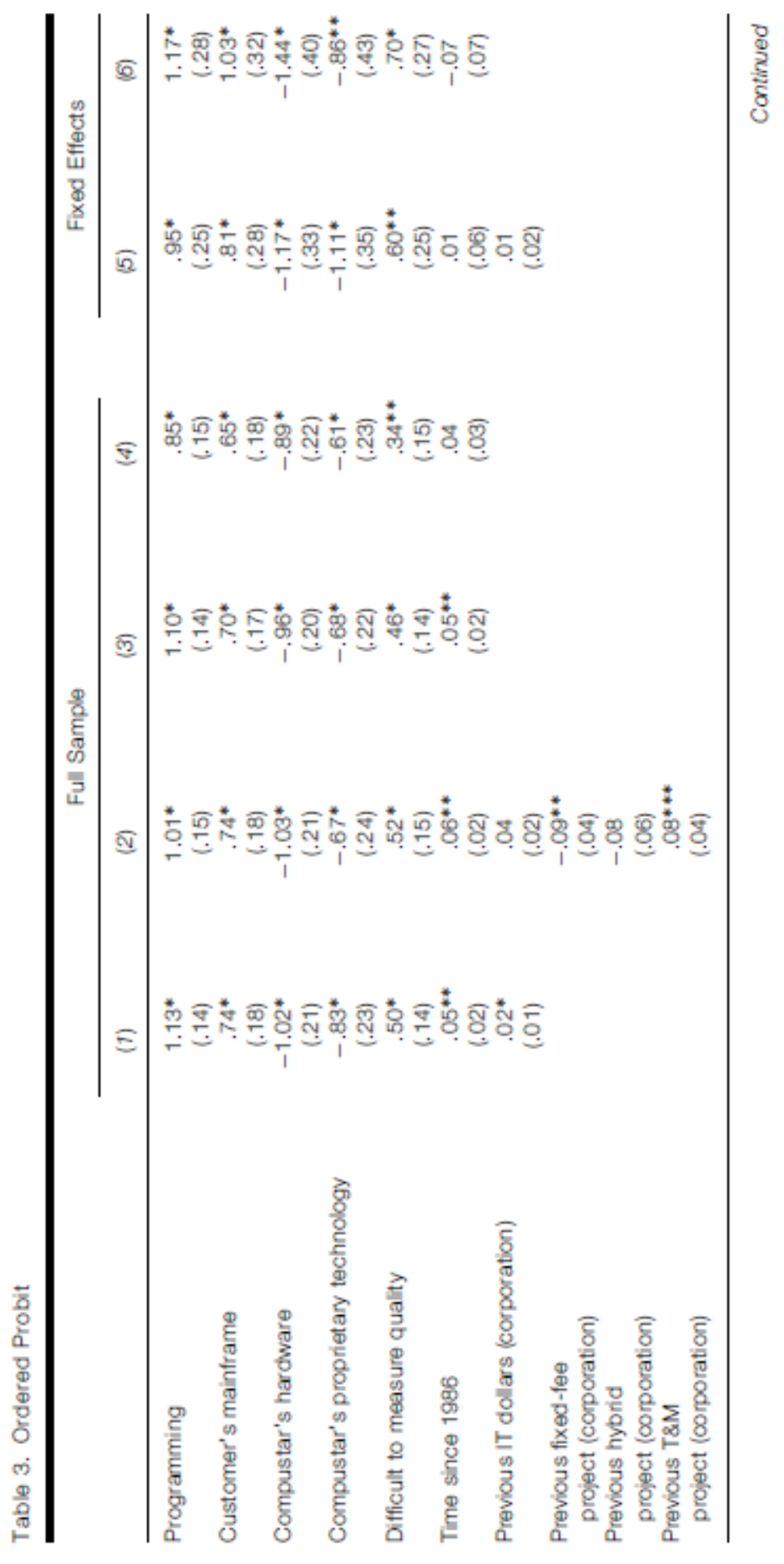




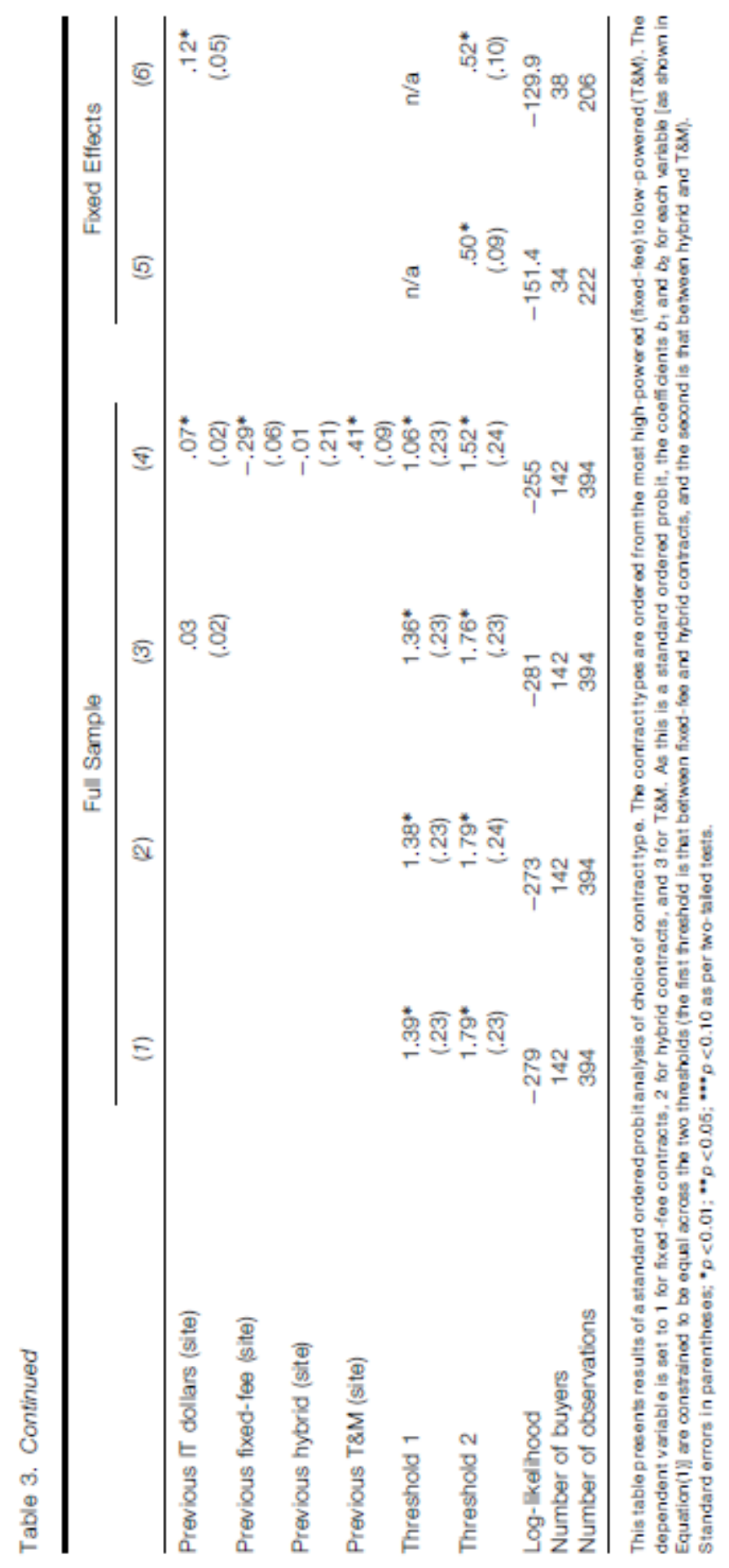

The results for the five uncertainty and measurement variables are very robust across all six regressions in Table 3. From Table 4, we observe that these variables are also economically meaningful. The first row of Table 4 presents a hypothetical baseline project (Baseline I) where all the five binary variables have a value of zero, while the site-specific relationship in dollars and the time variable are 
held at their means. In other words, if the project does not include programming, does not involve the customer's mainframe or Compustar's hardware or proprietary technology, and quality is not difficult to measure, the probability that a fixed-fee contract is used is 0.8 , using the coefficients from the third column of Table 3. The probability that a hybrid contract will be used is 0.09 and that a T\&M contract will be used is 0.11 . A different project identical in all ways to Baseline I but that involves programming will use a fixed-fee contract with a far lower probability of 0.4 ; the probability that a T\&M contract will be used greatly increased to 0.45 . The remainder of the first six rows of Table 4 can be interpreted similarly. The second set of rows in Table 4 presents a different baseline project (Baseline II) where all the five binary variables have a value of one, while the site-specific relationship in dollars and the time variable are again held at their means. If the project includes programming, a customer's mainframe, Compustar's hardware and proprietary technology, and quality is difficult to measure, the probability that a fixed-fee contract Is used is 0.58 . The probability that a hybrid contract will be used is 0.15 and that a T\&M contract will be used is 0.27 . A project identical to Baseline II but that does not involve programming will use a fixed-fee contract with a far higher probability of 0.91 ; the probability that a $T \& M$ contract will be used greatly decreases to 0.04 .

The fixed-effects columns of Table 4 also include a "mean" fixed effect evaluated across all 38 site-specific buyers in that subsample. These last three columns show probabilities based on the coefficients found in column 6 of Table 3. The predicted probabilities for the changes in the five binary variables are very similar in magnitude to those in the first three columns. Once again, these variables representing ex ante uncertainties and ex post difficulties to measure quality are shown to be economically meaningful in the choice of contract type.

We now turn to the variables measuring the significance of the relationship between Compustar and the buyers. The first column of Table 3 presents a model with the total dollar amount of all previous projects with a buyer corporation counted together as one variable, regardless of the type of contract or the location at which those projects took place. The third column presents results using a similar variable aggregated across contract types, but not across a buyer's locations. Here, each state within which a buyer corporation operates was counted as a distinct site-specific buyer. The corporate-level previous IT dollars variable in the first column was positive and significant, while the site-specific variable was just shy (at $\mathrm{P}<.11$ ) of statistical significance. However, the significance of the corporatelevel variable completely disappears when Compustar's largest buyer, with 42 contracts, is removed from the analysis. The site-specific variable, on the other hand, becomes significant if tills buyer is excluded. Further, once buyer-specific fixed effects are included, as shown in columns 5 and 6 of Table 3 , we observe that the site-specific relationship variable becomes significant, and the corporationspecific variable again loses its significance. 


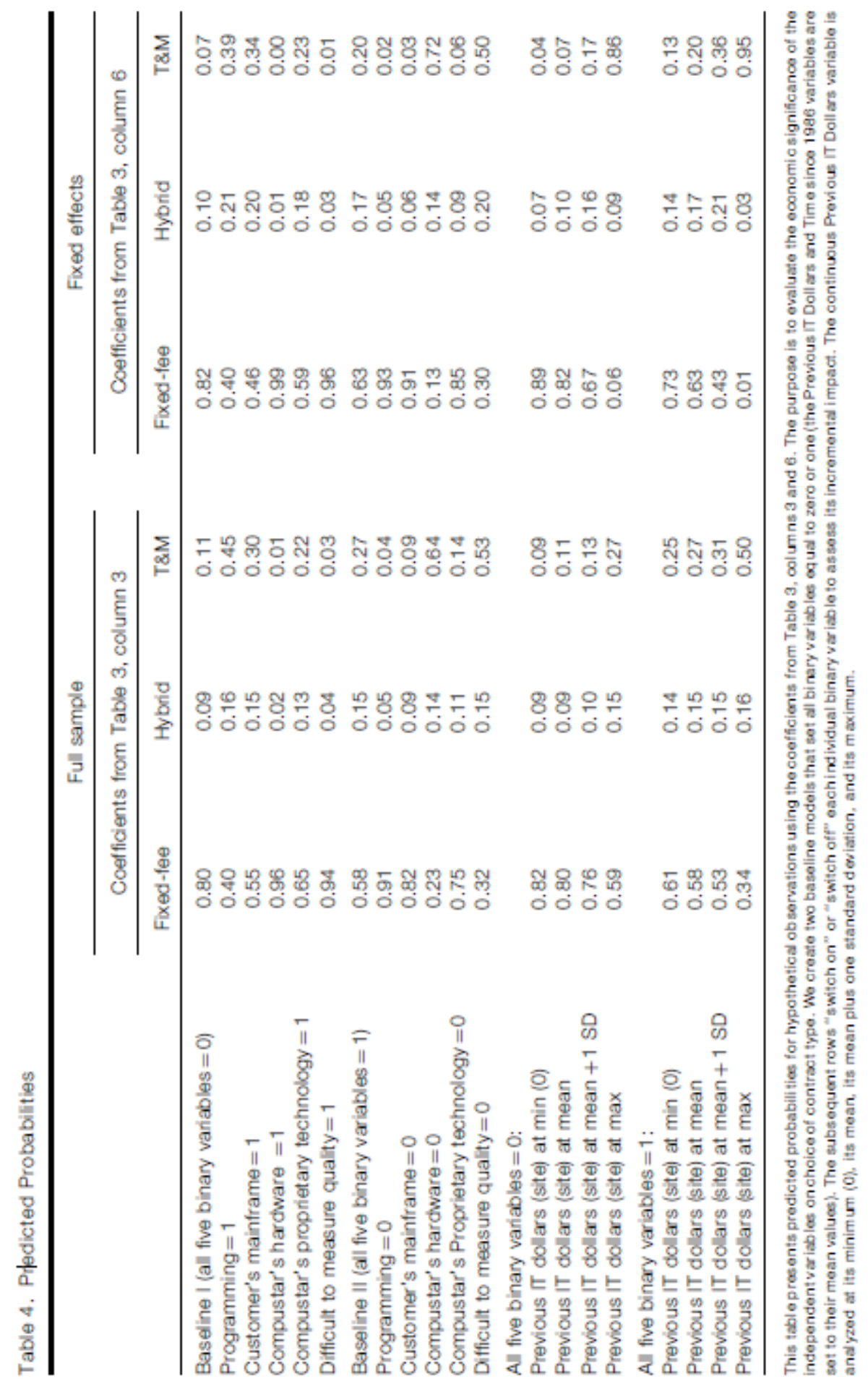

The second and fourth columns in Table 3 present results that count as separate variables the previous contracts of each type, in addition to including the previous IT dollars variable for each buyer 
that is aggregated across all contract types. The variables for previous fixed-fee, previous hybrid, and previous T\&M contracts in the second column aggregate those counts across all locations of each buyer corporation, while those in the fourth column count only those projects that have taken place at a specific location. We observe a strong correlation between the type of contract used in past transactions and the type of contract used for the current transaction. The previous contract type variables based on a specific buyer location, presented in the fourth column, are similar but more highly significant. While the coefficients of these variables may show some autoregressive bias and may capture site-specific heterogeneity, and thus cannot be directly interpreted, they remain useful control variables to test the robustness of the dollar relationship variable.

Turning to the bottom half of Table 4, the effect of relationships on contract choice is economically significant, but does not have the large effect in altering choice of contract type that the uncertainty and quality measurement variables had. Using the full sample of contracts, we observe that increasing the previous dollars spent by a site-specific buyer from the minimum $(\$ 0)$ to one standard deviation above the mean $(\$ 642,000)$ increases the likelihood that a T\&M contract is chosen from 0.09 to 0.13 (when the binary variables are all set to zero) and from 0.25 to 0.31 (when the binary variables are all set to one). However, as shown in the last three columns of the bottom half of Table 4, the subset of contracts between Compustar and those buyer sites that had more than one contract (and that did not have all contracts of the same type) showed a stronger effect of the previous relationship. Increasing the previous dollars spent by a site-specific buyer within this subset from the minimum of zero to one standard deviation above the mean increases the likelihood that a T\&M contract is chosen from 0.04 to 0.17 (when the binary variables are all set to zero) and from 0.13 to 0.36 (when the binary variables are all set to one). For this subset, at least, a substantial portion of the "within- buyer" variation in choice of contract type is explained by the dollar magnitude of the previous relationship.

In Table 5, we relax the restriction that coefficients for each variable have the same coefficient across the two thresholds. The coefficients $B_{1}$ (for the threshold between fixed-fee and hybrid) and $B_{2}$ (for the threshold between hybrid and T\&M) within the same regression are presented in separate columns. If both $B_{1}$ and $B_{2}$ are positive, then greater values of the independent variable lead to T\&M contracts, while negative values of both $B_{1}$ and $B_{2}$ lead to fixed-fee contracts. When $B_{1}$, is positive and $B_{2}$ is negative, then greater values of the variable are likely to lead to a higher probability of observing a hybrid contract. If $B_{1}$ is negative and $B_{2}$ is positive, then the variable leads to either polar contract type and away from hybrids. 


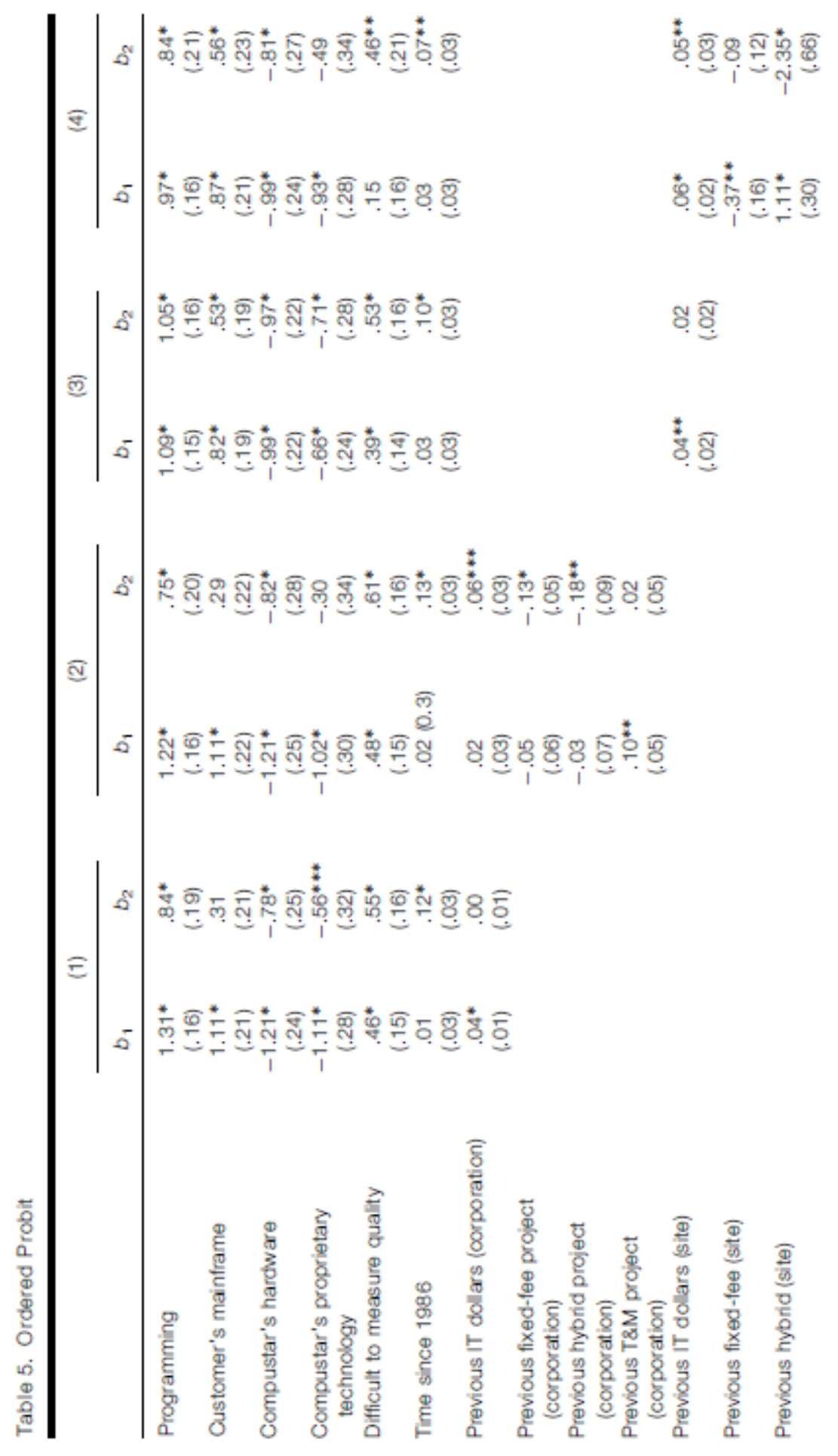




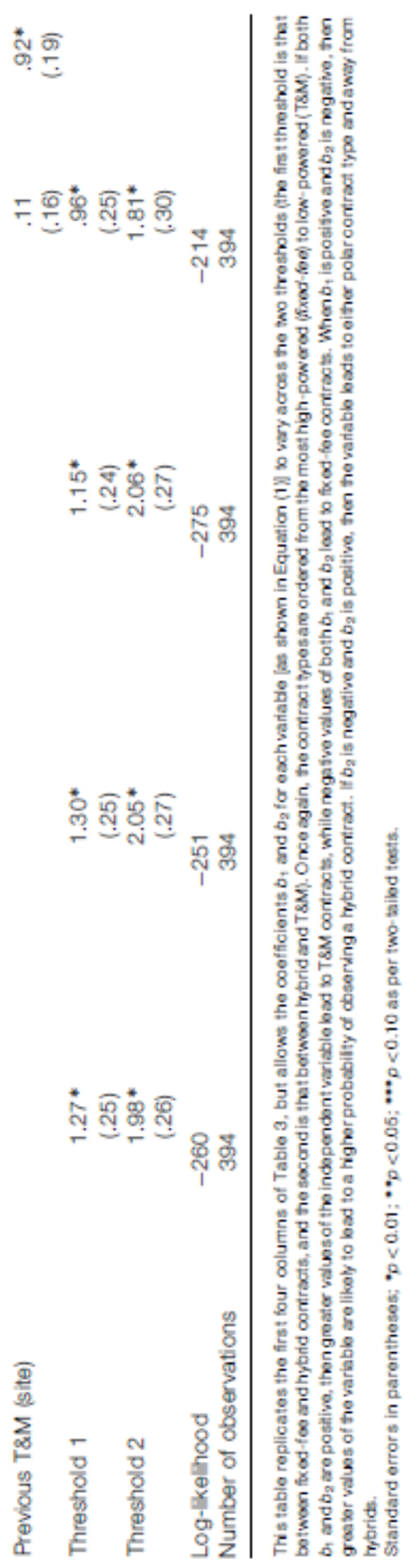

For the five binary variables representing uncertainty and difficulty of ex post quality measurement, the signs of the coefficients are completely consistent across the two thresholds. In addition, both coefficients for each of the first three variables, which measured complexity and uncertainty, are statistically significant. This indicates that the variables' effect on the choices between fixed-fee and hybrid and between hybrid and T\&M contracts are similar. Turning to the bottom half of 
Table 5, contrary to our prediction, we find that hybrid contracts do not serve as a form of insurance for new buyers. As with the five variables that examine ex ante uncertainty and ex post measurement costs, hybrid contracts are used at intermediate levels of a prior relationship. The results from the previous site-specific IT dollars variable indicate that the greater the buyer and supplier's previous experience with each other, the more likely they are to utilize lower-powered T\&M contracts instead of hybrid contracts.

While we do not present the results here, we also estimated regressions with each of the two largest buyer firms excluded from the analysis in the case for two separate coefficients with each variable. The results with respect to corporate-level previous IT dollars completely disappear. The results regarding all site-specific variables remain at the levels of significance reported above. Finally, the results are also robust to different methods of dealing with missing revenue data, such as giving these projects a value of $\$ 0$ or excluding them from the sample.

\section{Discussion}

Our basic results with regard to the incentive properties of contracts are consistent with previous findings in the contracting literature. When projects are complex, costs and final specifications of the deliverable are difficult to estimate in advance. In such cases, as measured by projects involving programming and customer mainframes and those not involving Compustar's own hardware or propriety technology, T\&M contracts with low-powered incentives are used more often. A related contribution in this dimension is that we confirm, rather than just assume, that hybrid contracts are more likely to be used at intermediate levels of ex ante cost uncertainty and ex post quality measurement difficulty.

We found that when transactions involve a firm's proprietary technology, the firms were more likely to select a fixed-fee contract. While this is consistent with the argument that proprietary technology reduces uncertainty, it is also interesting because another interpretation of this variable is that it captures an instance in which Compustar has private information about the costs of the transaction. Using this interpretation, our results are similar to Corts' (2002) finding that fixed-fee contracts between oil and gas exploration companies (the buyers) and contract drillers (the suppliers) become more prevalent with increased experience on the part of the drillers. While these findings are contrary to the predictions of economic models involving only a single buyer and supplier (e.g., Baron and Besanko, 1987), they are more consistent with models in which a buyer can choose among suppliers in a competitive bidding situation. McAfee and McMillan (1986) presented theory indicating that, given private information of each supplier regarding their technology, the likelihood of choosing higherpowered (fixed-fee) incentive contracts increases with the number of suppliers bidding for the project. If the buyer can select from among many suppliers, they can play suppliers off against one another and get them to reveal the quality of the technology.

We make two contributions in the area of previous relationships between the supplier and its buyers. First, site-specific measures of relationship magnitude (dollars spent on previous projects) push the parties toward lower-powered T\&M contracts. Corts and Singh (2004) found that the existence of a prior relationship between the buyer and the supplier lowers the cost of using both fixed-fee and T\&M contracts but does more to favor the use of the latter by serving as an alternative way to provide 
incentives to the supplier. As did Corts and Singh, we found that a relationship between the two parties does more to overcome the limitations of T\&M contracts than fixed-fee contracts. It appears to be the case that relationships serve to provide an alternative source of incentives for efficiency, the traditional weakness of T\&M contracts. The frequent, unanticipated disturbances in the IT industry may make the use of fixed-fee contracts problematic. The parties may assume that adjustment will be easy, but then find that it is not and turn to the lower-powered incentive properties of the hybrid and T\&M contracts.

Contrary to our predictions, the hybrid contract does not appear to serve as a form of insurance to new' buyers of IT services. Just as for the variables measuring complexity, the hybrid contracts arc used at an intermediate stage of a buyer/seller relationship between fixed-fee and T\&M contracts. Our second contribution relative to relationships and contract choice is the finding that the site-specific relationship variables consistently have more explanatory power than those variables measured at the corporate level. Consistent with anecdotal evidence and previous empirical work (e.g. Adams and Jaffe, 1996), our findings are consistent with the notion that the distance between various locations of a buyer firm acts as an impediment to communication regarding suppliers and contracts used.

A more thorough study of different types of contracts and when they are used would be a fruitful topic for future research. One contract used for a short time by Compustar was a percentage of savings contract. When a job called for Compustar to supply an activity that was designed to save the buyer money (e.g., a software audit), the firm and the buyer occasionally entered into a contract in which Compustar's revenue for the project was tied directly to how much money was saved. However, this contract broke down because of difficulties in measuring the realized cost savings, so Compustar discontinued it (the 11 contracts eliminated from our analysis were of this type). Examining other types of contracts and what incentive, risk, and other features they offer to facilitate different exchanges has been the focus of practitioner-oriented research, but this approach also holds promise for more rigorous empirical evaluation. 


\section{References}

Adams, James, and Adam Jaffe. 1996. "Bounding the Effects of R\&D: An Investigation Using Matched Establishment-Firm Data," 27 RAND Journal of Economics 700-21.

Adler, Paul S. 2001. "Market, Hierarchy, and Trust: The Knowledge Economy and the Future of Capitalism," 12 Organization Science 215-34.

Allen, Douglas W., and Dean Lueck. 1992a. "The Back-Forty on a Handshake: Specific Assets, Reputation, and the Structure of Farmland Contracts," 8 Journal of Law, Economics, \& Organization 366-76.

- 1992b. "Contract Choice in Modern Agriculture: Cash Rent versus Cropshare," 35 Journal of Law and Economics 397-426.

1993. "Transaction Costs and the Design of Cropshare Contracts," 24 RAND Journal of Economics $78-100$

Alston, Lee J., Samar K. Dutta, and Jeffrey B. Nugent. 1984. "Tenancy Choice in a Competitive Framework with Transaction Costs," 92 Journal of Political Economy $1121-33$.

Anderson, Erin. 1985. "The Salesperson as Outside Agent or Employee: A Transaction Cost Analysis," 4 Marketing Science 234-54.

Argyres, Nicholas S., and Julia P. Liebeskind. 1999. "Contractual Commitments, Bargaining Power, and Governance Inseparability: Incorporating History into Transaction Cost Theory," 24 Academy of Management Review 49-63.

Bajari, Patrick, and Stephen Tadelis. 2001. "Incentives versus Transaction Costs: A Theory of Procurement Contracts," 32 RAND Journal of Economics 387-407.

Baker, George, Robert Gibbons, and Kevin J. Murphy. 1994. "Subjective Performance Measures in Optimal Incentive Contracts,' 109 Quarterly Journal of Economics 1125-56.

2. 2002. "Relational Contracts and the Theory of the Firm," 117 Quarterly Journal of Economics 39-84.

Banerjex, Abhijit V., and Esther Duflo. 2000. "Reputation Effects and the Limits of Contracting: A Case Study of the Indian Software Industry," 115 Quarterly Journal of Economics 989-1017.

Baron, David P., and David Besanko. 1987. "Monitoring, Moral Hazard, Asymmetric Information, and Risk Sharing in Procurement Contracting," 18 RAND Journal of Economics 509-32.

Berends, T. C. 2000. "Cost Plus Incentive Fee Contracting-Experience and Structuring," 18 International Journal of Project Management 165-71.

Boerner, Christopher S., and Jeffrey T. Macher. 2002. "Transaction Cost Economics: An Assessment of Empirical Research in the Social Sciences," working paper, Georgetown University.

Cheung, Steven. 1969. "Transaction Costs, R isk Aversion, and the Choice of Contractual Arrangements," 12 Journal of Law and Economics 23-45.

Chisholm, Darlene C. 1997. "Profit-Sharing Versus Fixed-Payment Contracts: Evidencefrom the Motion Picture Industry," 13 Journal of Law, Economics, \& Organization 169-201.

Corts, Kenneth S. 2001. 'Fixed-Price vs. Cost-Plus: The Determinants of Contract Choice in Offshore Drilling," working paper 00-046, Harvard Business School.

Corts, Kenneth S., and Jasjit Singh. "The Effect of Repeated Interaction on Contract Choice: Evidence from Offshore Drilling," forthcoming in Journal of Law, Economics, \& Organization.

Crocker, Keith J., and Kenneth J. Reynolds. 1993. "The Efficiency of Incomplete Contracts: An Empirical Analysis of Air Force Engine Procurement," 24 RAND Journal of Economics 126-46.

Eswaran, Mukesh, and Ashok Kotwal. 1985. "A Theory of Contractual Structure in Agriculture," 75 American Economic Review 352-67.

Granovetter, Mark. 1985. "Economic Action and Social Structure: The Problem of Embeddedness," 91 American Journal of Sociology 481-510.

Gulati, Ranjay. 1995. "Does Familiarity Breed Trust? The Implications of Repeated Ties for Contractual Choice in Alliances,' 38 Academy of Management Journal 85-112.

Holmstrom, Bengt. 1979. "Moral Hazard and Observability," 10 Bell Journal of Economics $74-91$.

Laffont, Jean-Jacques, and Mohamed S. Matoussi. 1995. "Moral Hazard, Financial Constraints and Sharecropping in El Oulja,' 62 Review of Economics and Statistics $381-99$.

Lafontaine, Francine. 1992. "Agency Theory and Franchising: Some Empirical Results," 23 RAND Journal of Economics 263-83. 
Mayer, Kyle J. 1999. "Buyer-Supplier Relationships in High Technology Industries," PhD dissertation, University of California, Berkeley.

McAfee, R. Preston, and John McMillan. 1986. "Bidding for Contracts: A Principal-Agent Analysis," 17 RAND Journal of Economics 326-38.

Poppo, Laura, and Todd Zenger. 2002. "Substitutes or Complements? Exploring the Relationship Between Formal Contracts and Relational Governance," 23 Strategic Management Journal 707-25.

Reichelstein, Stefan. 1992. "Constructing Incentive Schemes for Government Contracts: An Application of Agency Theory," 67 Accounting Review 712-31.

Ring, Peter, and Andrew Van de Ven. 1994. "Developmental Processes of Cooperative Interorganizational Relationships," 19 Academy of Management Review 90-118.

Ryall, Michael, and Rachelle Sampson. 2003. "Do Prior Alliances Influence Contract Structure? Evidence from Technology Alliance Contracts" working paper, New York University.

Shelanski, Howard, and Peter G. Klein. 1995. "Empirical Research in Transaction Cost Economics: A Review and Assessment," 11 Journal of Law, Economics, \& Organization $335-61$.

Williamson, Oliver E. 1979. 'Transaction Cost Economics: The Governance of Contractual Relations," 22 Journal of Law and Economics 3-61.

- 1999. "Strategy Research: Governance and Competence Perspectives," 20 Strategic Management Journal 1087-108. 